FIVE THINKING MECHANISMS AS TECHNIQUES FOR DEVELOPING AN OUTLINE

\title{
Pana Pramulia
}

\author{
Universitas PGRI Adi Buana Surabaya, Indonesia \\ panapramulia@unipasby.ac.id
}

\begin{abstract}
A short story is a type of prose that does not have a lot of conflict and many characters in it, but it has a complex unanimity. However, writing a short story is not easy because it requires imaginative power and qualified creativity to express ideas and processing language. The imaginative process and creativity do not just exist but need to be trained intensively and continuously. There are several strategies for writing short stories, especially for beginner writers. The first strategy is compiling the outline of the essay, and the second one is using the technique of developing idea. One of the techniques to compile the outline of the essay is using "cilukba" pattern technique. Meanwhile, 5 thinking mechanisms is a technique used for developing an essay outline. This technique includes developing, omitting, increasing, decreasing, and sideways. This pattern was applied by PGSD students at Universitas PGRI Adi Buana registered in 2016 to write short stories. The methods included that (1) lecturers decided themes, (2) students were assigned to compile an outline based on "cilukba" patterns, (3) students were assigned to study the 5 thinking mechanism techniques, and (4) students were asked to arrange the outline based on the 5 thinking mechanism techniques. Based on this finding, PGSD students of Universitas PGRI Adi Buana Surabaya were able to write short stories and compiled the short stories into an ISBN collection book of short stories.
\end{abstract}

Keysword: short stories, “cilukba”, 5 thinking mechanisms

\section{LIMA MEKANISME PIKIR SEBAGAI TEKNIK PENGEMBANGAN KERANGKA KARANGAN}

\begin{abstract}
ABSTRAK
Cerpen merupakan salah satu jenis prosa yang tidak mengandung banyak konflik dan tidak banyak tokoh di dalamnya, tetapi memiliki kebulatan suara yang kompleks. Akan tetapi, menulis cerpen tidaklah mudah, karena membutuhkan daya imajinatif dan kreativitas yang mumpuni dalam mengungkapkan ide dan bahasa pengolahan. Proses imajinatif dan kreativitas tidak hanya ada, tetapi perlu dilatih secara intensif dan terus menerus. Ada banyak strategi dalam menulis cerpen, terutama bagi penulis pemula. Yang pertama menyusun garis besar esai, yang kedua menggunakan teknik pengembangan gagasan. Salah satu teknik dalam menyusun kerangka karangan adalah dengan menggunakan teknik pola cilukba. Untuk teknik pengembangan kerangka esai, Anda dapat menggunakan teknik 5 mekanisme berpikir. Teknik untuk 5 mekanisme berpikir, antara lain mengembangkan, menyusut, menambah, mengurangi, dan menyamping. Pola ini akan digunakan mahasiswa PGSD PGRI Universitas Adi Buana Surabaya angkatan 2016 untuk menulis cerpen. Metode yang digunakan antara lain dosen membuat tema, mahasiswa bertugas menyusun kerangka karangan berdasarkan pola cilukba, mahasiswa diberi tugas mempelajari 5 teknik mekanisme berpikir, dan mahasiswa bertugas menyusun kerangka karangan berdasarkan 5 teknik mekanisme berpikir. Berdasarkan hal tersebut, mahasiswa PGSD Universitas PGRI Universitas Adi Buana Surabaya angkatan 2016 dapat menulis cerpen dengan baik dan dapat mengumpulkan cerpen tersebut menjadi sebuah buku kumpulan ISBN cerpen.
\end{abstract}

Kata Kunci: cerpen, cilukba, 5 mekanisme berpikir

\begin{tabular}{|c|c|c|}
\hline Submitted & Accepted & Published \\
\hline 28 September 2020 & 22 November 2020 & 25 November 2020 \\
\hline
\end{tabular}

\begin{tabular}{|l|c|l|l|l} 
Citation & $:$ & Pramulia, P. (2020). Five Thinking Mechanisms as Techniques for Developing an Outline. Jurnal PAJAR (Pendidikan
\end{tabular} dan Pengajaran), 4(6), 1370-1377. DOI : http://dx.doi.org/10.33578/pjr.v4i6.8167.

\section{PENDAHULUAN}

Salah satu genre karya sastra, yaitu prosa yang di dalamnya ada jenis prosa yang disebut cerita pendek (cerpen). Bagi seseorang yang terbiasa menulis prosa, menulis cerita pendek cenderung lebih mudah daripada jenis prosa lainnya. Hal tersebut disebabkan, cerita pendek umumnya tidak mempunyai banyak konflik dan tidak banyak tokoh di dalamnya, tetapi mempunyai kebulatan cerita yang kompleks. Cerita pendek memang tidak sepanjang prosa lainnya, tetapi isinya merupakan kebulatan ide penulisnya (Meilasari, dkk, 2019). Kasnadi dan Sutejo (2010) menyatakan cerita pendek merupakan cerita yang panjangnya sekitar 5000 kata atau kira-kira 17 halaman kuarto spasi rangkap. 
Karya sastra ditulis berdasarkan imajinasi dan pengalaman, baik pengalaman terhadap peristiwa maupun kejiwaan (Pramulia, 2019). Bagi penulis pemula menulis cerita pendek bukan pekerjaan mudah, karena membutuhkan proses imajinatif dan daya kreatif yang mumpuni. Proses imajinatif dan daya kreatif tersebut tidak hadir begitu saja, melainkan butuh dilatih secara intensif dan terus menerus. Maka dari itu, penulis karya sastra bisa juga disebut sebagai imajinator dan kreator. Selain itu, proses imajinasi dan daya kreatif diperoleh dari pengalaman hidup penulis karya sastra. Dari latihan dan pengalaman seorang penulis dapat mengembangkan karyanya dengan mudah, serta membuat karya tersebut lebih bernilai.

Proses imajinatif dalam kepenulisan karya sastra membutuhkan kebiasaan dan latihan terus menerus, agar gagasan yang dimiliki dapat memberikan ledakan dan motivasi kepada pembaca (Pramulia, 2019). Penulis karya sastra harus mempunyai pengetahuan yang luas dan juga harus sebagai pembaca yang aktif, serta bergaul dengan banyak kalangan. Dari proses membaca, seorang penulis karya sastra akan banyak menemukan gagasan, perbendaharaan kosakata dan fenomena realitas. Dari proses bergaul dengan banyak kalangan akan banyak mendapatkan pemahaman karakter manusia dan menambah pengetahuan tentang fenomena peristiwa.

Karya sastra ditulis berdasarkan pengalaman penulisnya melalui peristiwa yang dialami, serta pengalaman kejiwaan untuk menilai dan menanggapi peristiwa tersebut. Setelah itu, penulis melakukan perenungan dan pengkajian lebih lanjut, agar karyanya mempunyai daya manfaat untuk pembaca. Untuk mencapai hal tersebut, penulis karya sastra biasanya menyusun kerangka karangan terlebih dahulu. Ada banyak teknik untuk menyusun kerangka karangan, salah satunya yaitu menggunakan teknik pola pikir cilukba. Pola pikir cilukba berfungsi untuk membuat kerangka gagasan. Cilukba merupakan struktur dasar narasi (Utami, 2018).

Cilukba diambil dari permainan masyarakat, di mana ketika orang tua/dewasa bermain-main dengan anak (balita). Cilukba merupakan permainan teka teki dari orang tua/dewasa kepada anaknya (balita). Terdapat tiga tahapan dalam permainan tersebut. Pertama "ci", di mana seorang anak masih melihat jelas wajah orang tuanya. Kedua "luk", ketika orang tua menutup (menyembunyikan) wajahnya dengan kedua telapak jari tangan. Ketiga "ba", di mana orang tua membuka telapak tangannya, sehingga wajahnya yang disembunyikan dapat dilihat kembali oleh anak. Artinya, $c i$ merupakan peristiwa sehari-hari, luk adalah konflik (ketegangan) yang dialami dalam kehidupan sehari-hari, dan $b a$ merupakan penyelesaian konflik.

Pola pikir cilukba tersebut merupakan teknik untuk menyusun kerangka karangan dengan urutan: 1) menceritakan kehidupan sehari-hari yang ditemui atau dialami; 2) menceritakan konflik yang terjadi; dan 3) menceritakan penyelesaian konflik tersebut. Setelah kerangka karangan disusun, langkah berikutnya penulis karya sastra mengembangkan kerangka tersebut menjadi sebuah cerita pendek. Banyak teknik untuk mengembangkan kerangka karangan, salah satunya yaitu teknik 5 mekanisme pikir. Teknik 5 mekanisme pikir, di antaranya mengembangkan, menciutkan, menaikkan, menurunkan, dan menyamping.

Mengembangkan merupakan cara kreatif untuk berpikir bahwa sesuatu yang kecil dan tidak bermakna dapat menjadi besar dan bermakna. Menciutkan merupakan teknik untuk mengurangi atau memperkecil permasalahan yang bertele-tele dan tidak penting untuk diceritakan. Menaikkan merupakan teknik untuk mengabstraktasi. Artinya, penulis diminta untuk mengubah hal yang denotatif menjadi konotatif. Menurunkan merupakan kebalikan dari teknik menaikkan, yaitu mengubah hal yang abstrak menjadi jelas. Menyamping adalah teknik untuk menceritakan kembali. Maksudnya, penulis dapat mengambil cerita lain (dongeng/legenda), kemudian diceritakan kembali berdasarkan bahasa sendiri. Setelah berhasil menceritakan dengan bahasa sendiri, cerita tersebut dapat disisipkan dalam cerpen yang ditulis. 
Teknik 5 mekanisme pikir tersebut akan diterapkan mahasiswa PGSD Universitas PGRI Adi Buana Surabaya Angkatan 2016 untuk mengembangkan kerangka karangan yang telah disusun sebelumnya. Seperti yang telah diuraikan, bahwa penyusunan kerangka karangan berdasarkan teknik pola pikir cilukba. Mahasiswa tersebut pada semester genap 2019/2020 menempuh mata kuliah Kreativitas Sastra Anak, di mana mempunyai tugas akhir untuk menyusun buku antologi cerita pendek yang ber-ISBN. Buku kumpulan tersebut diharapkan dapat lebih baik daripada buku kumpulan cerpen sebelumnya.

\section{KAJIAN TEORETIS}

\section{Teknik 5 Mekanisme Pikir}

Alur penceritaan, penyajian konflik beserta penyelesaian, dan penyajian karakter tokoh merupakan bagian utama dalam penulisan cerita pendek. Alur penceritaan harus memikat agar pembaca tidak mengalami kebosanan saat membaca. Penyajian konflik dan penyelesaian konflik harus digarap secara dramatic agar cerita pendek mempunyai titik ledak mengesankan. Karakter tokoh, baik protagonis maupun antagonis harus diciptakan dengan kuat agar melekat di dalam hati pembaca. Selain itu, penggarapan bahasa merupakan salah satu karakter penting dalam penulisan cerita pendek. Masalah penggarapan bahasa sebagai sarana utama fiksi berkaitan dengan gaya bahasa. Bagaimana penulis memilih sarana pengucapannya sehingga permasalahan yang dikemukakan dapat tertuang melalui bentukan narasi penulis dan atau dialog para tokoh dalam fiksi (Azmy dkk, 2017). Penggarapan bahasa, alur penceritaan, penyajian konflik beserta penyelesaiannya yang di dalamnya terdapat tokoh beserta karakternya dapat menggunakan teknik 5 mekanisme pikir.

5 mekanisme pikir digunakan untuk mengembangkan kerangka karangan dan juga digunakan untuk memoles isi dari cerita pendek agar menarik. 5 mekanisme pikir tersebut digunakan untuk menyusun cerita pendek secara bulat dan kompleks dengan diksi-diksi yang sesuai dengan kaidah keindahan. 5 mekanisme pikir merupakan teknik lanjutan dari pola pikir sebelumnya, yaitu pola pikir cilukba. 5 mekanisme pikir diterapkan setelah hasil dari pola pikir cilukba selesai. 5 mekanisme pikir, antara lain mengembangkan, menciutkan, menaikkan, menurunkan, dan menyamping.

Mengembangkan merupakan cara kreatif untuk berpikir bahwa sesuatu yang kecil dan tidak bermakna dapat menjadi besar dan bermakna. Dapat dikatakan, pola mengembangkan ini banyak menggunakan majas hiperbola. Fungsi dari pola ini untuk mendramatisasi cerita agar pembaca tertarik membaca dari awal sampai akhir cerita. Misalnya, jika penulis membuat tokoh protagonis yang dalam hidupnya sengsara, maka berdasarkan pola ini penulis akan membuat kesengsaraan tersebut berkali-kali lipat, sehingga pembaca akan merasa geregetan.

Menciutkan merupakan teknik untuk mengurangi atau memperkecil permasalahan yang bertele-tele dan tidak penting untuk diceritakan. Pola ini merupakan kebalikan dari pola mengembangkan. Biasanya pola menciutkan digunakan setelah cerita pendek yang ditulis selesai. Pada proses pengoreksian (pembacaan ulang) penulis dapat memperpadat bahkan menghapus cerita atau konflik yang tidak perlu. Artinya, pola ini bertujuan untuk meminimalisasi alur cerita, isi cerita, dan konflik yang membosankan pembaca.

Menaikkan merupakan teknik untuk mengabstraktasi. Artinya, penulis diminta untuk mengubah hal yang denotatif menjadi konotatif. Pada pola ini penulis karya sastra banyak menggunakan majas metafora untuk menyusun bahasa. Hal tersebut bertujuan agar cerita yang disajikan mempunyai kesan indah dan menarik. Selain itu, pola menaikkan akan dapat membuat pembaca penasaran menemukan makna dan maksud dari cerita, karena cerita yang disajikan menggunakan bahasa kiasan atau simbolik.

Menurunkan merupakan kebalikan dari teknik menaikkan, yaitu mengubah hal yang abstrak menjadi jelas. Cerita pendek berbeda dengan puisi, makanya tidak semua cerita disajikan menggunakan bahasa kiasan, tetapi juga banyak menyajikan bahasa-bahasa yang mudah dipahami pembaca. Bahkan, tidak jarang penulis 
menggunakan bahasa slank yang dapat menarik perhatian pembaca. Pola menurunkan ini biasanya digunakan penulis setelah cerita yang ditulis selesai. Artinya, penulis merevisi cerita-cerita yang masih membingungkan pembaca, tetapi tidak disajikan dengan indah.

Menyamping adalah teknik untuk menceritakan kembali. Dalam hal ini, penulis dapat mengambil cerita lainnya, bisa dongeng atau legenda masyarakat, kemudian diceritakan kembali berdasarkan bahasa sendiri. Setelah berhasil menceritakan dengan bahasa sendiri, cerita tersebut dapat disisipkan dalam cerpen yang ditulis. Pola ini juga dapat digunakan untuk mentransformasikan cerita dalam film menjadi narasi prosa.

Teknik 5 mekanisme pikir di atas akan digunakan mahasiswa PGSD Universitas PGRI Adi Buana Surabaya Angkatan 2016 untuk menulis cerita pendek pada mata kuliah Kreativitas Sastra Anak. Mata kuliah tersebut ditempuh pada semester 8 dengan tugas akhir membuat buku kumpulan cerita pendek. Sebelum menulis cerita pendek, mahasiswa telah membuat kerangka karangan berdasarkan pola pikir cilukba yang telah didapat pada pertemuan pertama.

\section{METODE PENELITIAN}

Penelitian ini merupakan penelitian deskriptif. Metode yang digunakan berupa tes projek. Data diperoleh berdasarkan tugas akhir mahasiswa PGSD angkatan 2016 yang menempuh mata kuliah Kreativitas Sastra Anak. Tugas akhir mahasiswa, yaitu menulis cerita pendek yang kemudian dijadikan buku kumpulan cerita pendek. Subjek penelitian adalah mahasiswa berjumlah 36. Teknik pengumpulan data menggunakan cara mahasiswa mengumpulkan tugas, baik kerangka karangan maupun cerita pendek tanpa teknik apapun dan setelahnya mengumpulkan kerangka karangan berdasarkan teknik cilukba dan cerita pendek berdasarkan teknik 5 mekanisme pikir.

Pengumpulan tugas dilakukan dengan dua model, yaitu dalam bentuk hard file (kertas) dan soft file yang dikirimkan ke surat elektronik panapramulia@unipasby.ac.id. $\quad$ Tujuan pengiriman tugas dengan dua model tersebut bertujuan mengantisipasi hilangnya hard file.

Tahap selanjutnya melakukan pengamatan data yang diperoleh dari hard file. Selain pengumpulan data melalui tugas, dosen juga mencatat presentasi dan kendala mahasiswa dalam mengembangkan kerangka karangan.

\section{HASIL DAN PEMBAHASAN}

Pertama yang dilakukan dosen sekaligus peneliti, yaitu memberikan gambaran umum mengenai cerita pendek. Kedua, mahasiswa menjelaskan kembali mengenai hakikat cerita pendek. Ketiga, dosen memberikan tema besar untuk penulisan cerita pendek. Keempat, mahasiswa bertugas menyusun kerangka karangan. Kelima, mahasiswa ditugasi mengembangkan kerangka karangan menjadi cerita pendek.

Kerangka karangan dan cerita pendek yang telah dikerjakan mahasiswa dikumpulkan untuk kemudian dikoreksi lebih lanjut. Beberapa catatan sebagai berikut.

1. 17 kerangka karangan tidak sesuai tema yang telah ditentukan.

2. Semua cerita pendek tidak menyusun alur dengan baik.

3. 24 cerita pendek tidak berhasil menyajikan konflik.

4. 13 cerita pendek tidak mempunyai karakter tokoh yang kuat.

5. 32 cerita pendek belum menyajikan bahasa yang estetis.

6. 21 cerita pendek belum menggambarkan nilai dan norma yang dapat dipahami anak-anak dengan mudah.

Berdasarkan temuan tersebut, peneliti membuat catatan dan dipresentasikan kepada mahasiswa sebagai pijakan menulis cerita pendek selanjutnya. Peneliti juga menjelaskan kembali gambaran tema yang telah ditentukan agar mahasiswa tidak keliru memahami.

Pada pertemuan berikutnya, peneliti memberikan gambaran dan menjelaskan cara menyusun kerangka karangan berdasarkan teknik cilukba, serta menjelaskan teknik 5 mekanisme pikir. Langkah selanjutnya, mahasiswa diberi tugas merangkum teknik cilukba dan teknik 5 
mekanisme pikir yang kemudian dipresentasikan di depan kelas.

Setelah dinyatakan memahami, mahasiswa diberi tugas menyusun kerangka karangan dan mengembangkan kerangka karangan tersebut menjadi cerita pendek. Hasil karya kerangka karangan dan cerita pendek mahasiswa berdasarkan teknik cilukba dan teknik 5 mekanisme pikir sebagai berikut.

1. 36 kerangka karangan sesuai tema.

2. 36 kerangka karangan disusun berdasarkan teknik cilukba.

3. 29 alur cerita pendek disusun secara sistematis berdasarkan teknik 5 mekanisme pikir.

4. 27 cerita pendek mempunyai karakter tokoh yang kuat.

5. 25 cerita pendek menyajikan bahasa yang estetis.

6. 36 cerita pendek menyajikan nilai dan norma yang mudah dipahami anak-anak.

Berikut dua cerita pendek terbaik berdasarkan parameter penilaian yang telah ditentukan.

1. Ide Pintar Mama Farel ditulis oleh Debora Natalia Prastica (NIM: 168000065)

\section{Kerangka Karangan}

Ci : Libur sekolah dasa diperpanjang karena pandemik covid 19.

Luk : Farel lebih banyak menghabiskan waktunya dengan bermain gadget.

Ba : Farel dinasihati mama untuk mengurangi bermain gadget dan mengimbangi dengan belajar serta olahraga di dalam rumah.

\section{Pengembangan Gagasan}

Ci : 1. Libur Sekolah Dasar diperpanjang, karena pandemik covid 19 menerjang. Para siswa mengikuti kegiatan belajar di rumah secara daring.

2. Wajah Farel terlihat sumringah. Berarti ia punya waktu panjang untuk bermain.

3. Mama Farel resah, gelisah dan wajahnya gundah, karena Farel tidak pernah mengulang pelajaran daring yang belum dipahami.

Luk : 1. Di rumah Farel malas sekali belajar. Farel lebih banyak menghabiskan waktunya dengan bermain gadget seharian penuh.

2. Kemudian Mama Farel mempunyai ide agar Farel memiliki minat belajar yang tinggi dan mengurangi untuk bermain gadget. Ketika malam tiba, Farel yang sudah tertidur dengan pulas.

3. Mama Farel bergegas melakukan idenya yaitu dengan memberi make up warna hitam di bawah mata Farel agar seolah-olah mata itu terlihat bengkak.

4. Keeseokan harinya saat Farel bangun dari tidur, ia langsung menuju kamar mandi untuk buang air kecil. Betapa kaget Farel saat menatap wajahnya dikaca dengan keadaan mata berwarna hitam dan bengkak.

Ba : 1. Sambil berpura-pura mengobati Farel, mamanya menjelaskan sebab matanya berubah menjadi seperti itu karena terlalu sering bermain gadget hingga lupa waktu. 
2. Mamanya memberi nasihat agar Farel mengurangi bermain gadget dan menggantinya dengan serius belajar secara daring maupun mandiri, serta berolahraga untuk menjaga kebugaran.

3. Akhirnya Farel menuruti nasihat mamanya.

Berdasarkan penggalan cerita pendek dari Debora Natalia Prastica yang berjudul Ide Pintar Mama Farel di atas, teknik cilukba dapat digunakan dengan baik, sehingga tidak terlalu sulit mengembangkan kerangka karangan menggunakan teknik 5 mekanisme pikir. Kaidahkaidah mengembangkan, menciutkan, menaikkan, menurunkan, dan menyamping berhasil diadopsi dengan baik, sehingga alur cerita sistematis, karakter tokoh kuat, bahasa yang digunakan estetis dan mudah dipahami anak-anak, dan norma serta nilai dapat disajikan dengan baik.

Dari sini dapat dikatakan, bahwa penggunaan teknik 5 mekanisme pikir bergantung pada keberhasilan menyusun kerangka karangan. Artinya, teknik cilukba berperan penting dalam keberhasilan menuangkan gagasan.

2. Episode Satu Babak ditulis oleh Nadlatul Ilma (NIM: 168000087)

\section{Kerangka Karangan}

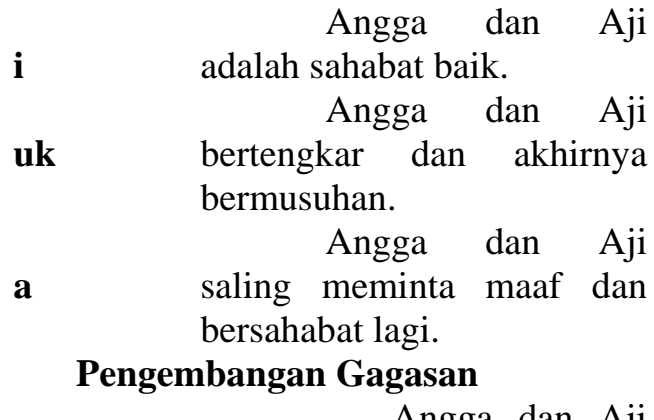

$$
\text { Angga dan Aji }
$$

i . adalah sahabat baik di kampungnya. Dulu Angga pernah berkata bahwa tidak ada teman uk

yang sebaik Aji. Aji pun

tidak kalah dalam memuji Angga.

Kata Aji, kalau ada sepuluh anak seperti Angga di kampungnya, maka Perang Dunia Ketiga tidak bakal meletus.

Mungkin ibarat petasan, baru dinyalakan sumbunya. Sudah jelas, terompet peperangan sudah ditiup antara Angga dan Aji. Keduanya sudah menyatakan putus tali persahabatan. Mereka musuhan antara satu dengan yang lainnya.

Sudah seminggu lamanya Angga dan Aji tidak terlihat bermain bersama. Jika bermain, kalau ada Angga pasti tidak ada Aji. Begitu sebaliknya.

Bubby dan Komo berniat mengadu Angga dan Aji untuk berkelahi.

Angga dan Aji dipertemukan di sebuah lapangan. Satu pihak menjagokan Angga, dan pihak lain menjagokan Aji.

\section{Sebelum}

berkelahi, Angga dan Aji berpikir sejenak. Mereka tampak merenung sangat dalam.

Suara guru ngaji tiba-tiba berputar-putar masuk ke dalam telinga mereka. "Kita sebagai manusia harus rukun, jangan saling 


menyakiti," begitulah
suara itu yang akhirnya
membuat Angga dan Aji
tersadar dari
kekhilafannya. An Aji
Angga dan Aji
saling mengulurkan
tangan. Keduanya saling
berjabat tangan. Lama
sekali keduanya saling
berbisik dan
mengedipkan mata.
Mereka saling
meminta maaf dan
memaafkan dan teman-
temannya bertepuk
tangan.

Cerita pendek yang berjudul Episode satu Babak karya Nadlatul Ilma di atas disusun sesuai parameter yang telah ditentukan. Kerangka karangan yang dibuat berdasarkan teknik cilukba sederhana, tetapi kuat. Dari kerangka karangan yang kuat tersebut, teknik 5 mekanisme pikir mudah digunakan sebagai alat pengembangan gagasan.

Berdasarkan penggalan pengembangan gagasan di atas dapat dikatakan, bahwa cerita pendek Episode Satu Babak telah memenuhi kriteria penilaian yang ditentukan. Mengembangkan, menciutkan, menaikkan, menurunkan, dan menyamping dapat dibaca secara sistematis dan jelas. Alur cerita, bahasa yang disajikan, karakter tokoh, serta pesan dan nilai menjadi satu kesatuan yang utuh.

\section{Pembahasan}

Data primer dalam penelitian ini, yaitu cerita pendek karya mahasiswa PGSD Universitas PGRI Adi Buana Surabaya Angkatan 2016 yang menempuh mata kuliah pilihan Kreativitas Sastra Anak. Penulisan cerita pendek tersebut berdasarkan dua teknik yang telah diberikan, yaitu teknik cilukba sebagai alat menyusun kerangka karangan, dan teknik 5 mekanisme pikir sebagai alat mengembangkan kerangka karangan.

Pembahasan fokus pada keterkaitan antara du teknik tersebut dengan penyajian cerita pendek. Berdasarkan parameter penilaian yang telah ditentukan, antara lain keterkaitan isi dengan tema, alur cerita, bahasa, dan norma dan nilai bahwa cerita pendek yang ditulis mahasiswa PGSD Angkatan 2016 dapat dikatakan berhasil dan baik.

Cerita pendek mahasiswa PGSD Angkatan 2016 secara keseluruhan sesuai dengan tema yang telah ditentukan. Alur cerita (27 cerpen) dirangkai dengan sistematis dan rapi, karakter tokoh (29 cerpen) disajikan dengan kuat. Cerita pendek ( 25 cerpen) menyajikan diksi yang estetis dan mudah dipahami anak-anak. Secara keseluruhan cerita pendek memberikan pesanpesan kebaikan, menyajikan norma dan nilai-nilai yang dapat dijadikan pembelajaran pembacanya, terutama anak-anak.

36 cerita pendek yang telah ditulis dan dinilai tersebut dikumpulkan menjadi sebuah buku kumpulan cerita pendek ber-ISBN. Judul buku yaitu Episode Satu Babak, Covid 19 dan Banjir Kiriman Kisah lainnya, yang diterbitkan oleh Pagan Press dan ber-ISBN: 978623756474 4 (Mahasiswa PGSD Angkatan 2016:2020).

\section{SIMPULAN DAN REKOMENDASI}

Bagi pemula menulis sebuah cerita pendek bukan pekerjaan yang mudah, maka penulis pemula membutuhkan teknik khusus untuk mempermudah menulis cerita pendek. Teknik cilukba dapat digunakan penulis pemula untuk menyusun kerangka karangan, dan untuk mengembangkan kerangka karangan tersebut dapat menggunkan teknik 5 mekanisme pikir. Dua teknik tersebut digunakan mahasiswa PGSD Univeristas PGRI Adi Buana Surabaya untuk menulis cerita pendek. Dapat dikatakan mahasiswa PGSD Angkatan 2016 berhasil dengan baik menggunakan dua teknik tersebut. Artinya, mahasiswa dapat dengan mudah menyusun kerangka karangan, mengembangkan kerangka karangan, menciutkan dan memadatkan konflik, menaikkan bahasa sedemikian rupa, menurunkan tensi konflik, serta dapat menggunakan pola menyamping untuk menyajikan pesan dan nilai yang proporsional dapat dipahami anak-anak. 


\section{DAFTAR PUSTAKA}

Azmy, B., dkk. (2017). Bahasa dan Sastra Indonesia (Teori daan Paradigma Bahasa dan Sastra Indonesia untuk PGSD). Surabaya: Adi Buana University Press.

Kasnadi dan Sutejo. (2010). Kajian Prosa: Kiat Menyisir Dunia Prosa. Yogyakarta: Pustaka Felicha.

Mahasiswa PGSD Angkatan 2016. (2020). Episode Satu Babak, Covid 19, dan Banjir Kiriman Kisah Lainnya. Lamongan: Pagan Press.

Meilasari, N. R., Junianto, J., \& Mustika, I. (2019). Efektivitas Penggunaan Metode Image Streaming dalam Pembelajaran Menulis Cerita Pendek pada Siswa Kelas XI SMA Darul Falah Cihampelas. Parole (Jurnal Pendidikan Bahasa dan Sastra Indonesia), 1(5), 707-712.

Pramulia, P. (2019). Teknik Cilukba dan Teknik Empat Pola Pikir Matematika Untuk Menulis Cerita Pendek. EduStream: Jurnal Pendidikan Dasar, Volume III Nomor 2 November 2019, Halaman 6471.

https://journal.unesa.ac.id/index.php/jpd/a rticle/view/6516

Pramulia, P. (2019). Pola Pikir Cilukba Dan Empat Pola Pikir Matematika Sebagai Teknik Penulisan Cerita Pendek. SNHRP, 230-237.

Utami, A. (2018). Menulis dan Berpikir Kreatif: Spiritualisme Kritis. Jakarta: KPG. 